\title{
Crucial role of temporary airborne infection isolation rooms in an intensive care unit: containing the COVID-19 outbreak in South Korea
}

\author{
Shin Yup Lee ${ }^{1,2}$, Sun Ha Choi ${ }^{1,2}$, Ji Eun Park ${ }^{1,2}$, Soyoon Hwang ${ }^{2,3,4}$ and Ki Tae Kwon ${ }^{2,3,4^{*}}$ (1)
}

From 20 February through 9 March 2020, South Korea reported the highest number of patients confirmed with coronavirus disease 2019 (COVID-19) outside China, mainly in the Daegu city area: this was a disease cluster related to the practices of the Shincheonjii religious group [1-3]. In Daegu city, the number of patients with COVID-19 increased rapidly and saturated the healthcare system; as a result, some critically ill patients were unable to obtain hospital care and as a result died of this disease. Care for critically ill COVID-19 patients requires intensive care units (ICUs) that are equipped with airborne infection isolation rooms (AIIRs) $[4,5]$. To cope with this situation, we assembled temporary AIIRs with mobile negative-air machines in our ICU, as was done previously in Korea during the Middle East Respiratory Syndrome (MERS) outbreak [6]. Here, we share our experiences with the assembly of temporary AIIRs in the ICU of our single 635-bed tertiary care, academic hospital and discuss the critical role played by these units toward controlling this explosive outbreak. We hope that our findings will serve as a reference for areas where the COVID-19 outbreak remains ongoing.

Before the COVID-19 outbreak, Daegu had only three AIIRs with anteroom in an ICU of one national university hospital; these were built with government support after the 2015 MERS outbreak. The tertiary hospitals in Daegu facilitated the isolation and treatment severely ill

\footnotetext{
* Correspondence: ktkwon@knu.ac.kr

${ }^{2}$ Department of Internal Medicine, School of Medicine, Kyungpook National University, Daegu, Korea

${ }^{3}$ Division of Infectious Diseases, Kyungpook National University Chilgok Hospital, 807 Hokuk-ro, Buk-gu, Daegu 41404, Korea

Full list of author information is available at the end of the article
}

patients via temporarily remodeling of existing ICU facilities. Prior to the outbreak, our hospital operated two separate ICU facilities; each was equipped with two AIIRs without anterooms. This was not sufficient for isolation of COVID-19 patients nor did this provide appropriate protection for healthcare workers (HCWs). We decided to remodel one of the two ICUs to facilitate isolation of critically ill COVID-19 patients. Schematic view of the renovated ICU was illustrated in Fig. 1. Critically ill COVID-19 patients were transported to the temporary negative pressure isolation ICU in negative pressure carts that utilized an exclusive path and elevator maintained for this purpose by staff members wearing appropriate personal protective equipment. The COVID-19 team included 5 physicians and 40 nurses. All HCWs in our newly remodeled ICU were screened for COVID-19 via the reverse transcriptase-polymerase chain reaction test after the first 2 weeks on duty; no tests were reported as positive.

Approximately $60 \%$ of the COVID-19 patients at our hospital had severe pneumonia (respiratory rate $>30$ breaths/min, severe respiratory distress, or $\mathrm{SpO}_{2} \leq 93 \%$ on room air). Before the AIIRs in the ICU opened in our hospital, we had no choice but to treat these patients in preexisting AIIRs located with the general hospital ward. Upon completion of this renovation, we were able to hospitalize all critically ill COVID-19 patients and to provide timely and appropriate management and support. Our newly renovated temporary AIIRs have been in operation for 4 weeks. During this time, we treated seven patients: six patients have required mechanical ventilation, two patients were treated with extracorporeal membrane oxygenation, and continuous renal 


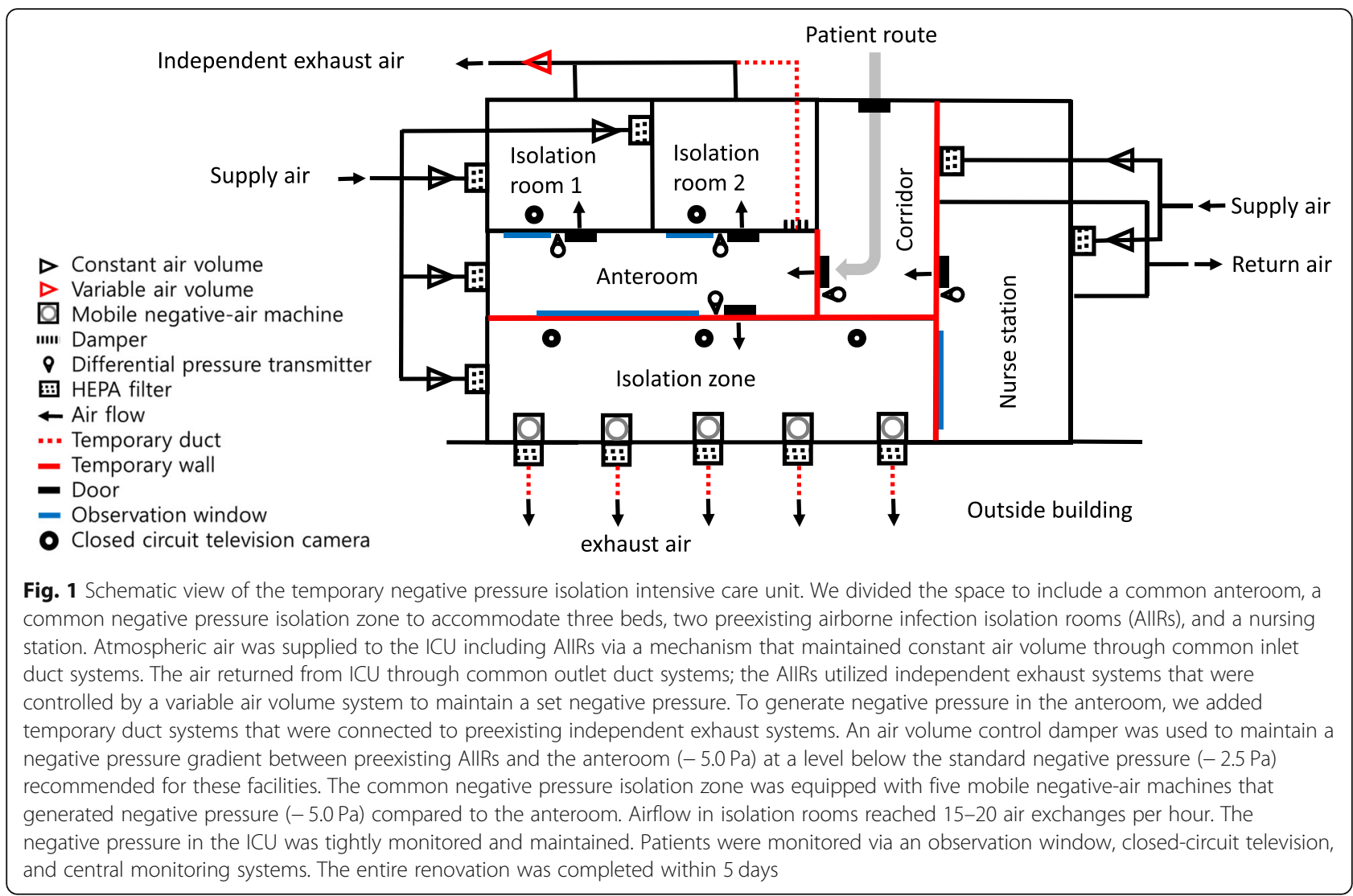

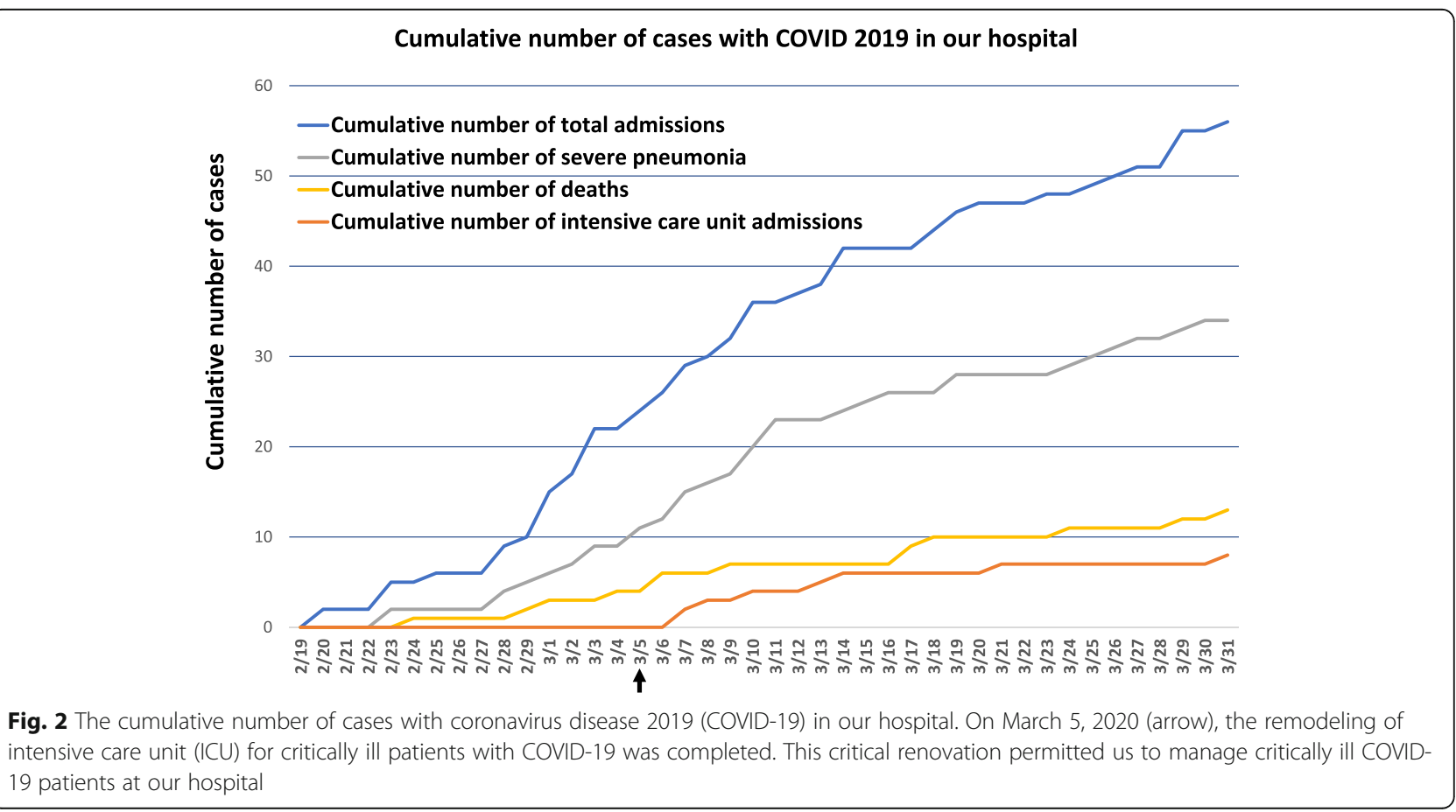


replacement therapy has been provided to one patient. We believe that the urgently renovated ICU played an important role in preventing the surge of mortality despite the rapid increasing number of patients with severe pneumonia (Fig. 2).

In conclusion, our experience suggests that renovation of our ICUs to include temporary AIIRs was a critical and highly effective measure that permitted us to react appropriately to the explosive outbreak of COVID-19 and to provide optimal care for severely ill patients. We hope that our experience will help to prepare physicians and hospitals worldwide for the unprecedented crisis of the COVID-19 pandemic.

\section{Abbreviations}

COVID-19: Coronavirus disease 2019; ICU: Intensive care unit; AllRs: Airborne infection isolation rooms; MERS: Middle East Respiratory Syndrome; HCWs: Healthcare workers

\section{Acknowledgements}

We appreciate the devoted administrative support of Jin Ho Sohn, the president of Kyungpook National University Chilgok Hospital, and Gyu-Seog Choi, the director of Clinical Services. We also appreciate the contributions and dedication of all members of the hospital facility engineering team and the ICU team.

\section{Authors' contributions}

Lee SY and Kwon KT are involved in the process of ICU remodeling. Lee SY and Kwon KT conceptualized this research and drafted the manuscript. Cho SH, Park JE, and H S analyzed the data, reviewed and edited the manuscript. All authors read and approved the final manuscript.

\section{Authors' information}

Shin Yup Lee is the director of Division of Pulmonary and Critical Care Medicine in Kyungpook National University Chilgok Hospital, Daegu, Korea. Ki Tae Kwon is the director of Department of Infection Control in Kyungpook National University Chilgok Hospital, Daegu, Korea.

\section{Funding}

"Not applicable"

\section{Availability of data and materials}

The data are available from the corresponding author.

\section{Ethics approval and consent to participate}

This study was exempt from the review by Institutional Review Board of the Kyungpook National University Chilgok Hospital (KNUCH 2020-04-001).

\section{Consent for publication}

"Not applicable"

\section{Competing interests}

The authors declare that they have no competing interests.

\section{Author details}

'Division of Pulmonary and Critical Care Medicine, Kyungpook National University Chilgok Hospital, Daegu, Korea. ${ }^{2}$ Department of Internal Medicine, School of Medicine, Kyungpook National University, Daegu, Korea. ${ }^{3}$ Division of Infectious Diseases, Kyungpook National University Chilgok Hospital, 807 Hokuk-ro, Buk-gu, Daegu 41404, Korea. ${ }^{4}$ Department of Infection Control, Kyungpook National University Chilgok Hospital, Daegu, Korea.
Received: 25 April 2020 Accepted: 1 May 2020

Published online: 18 May 2020

\section{References}

1. World Health Organization (WHO): Coronavirus disease 2019 (COVID-19) situation report-49. 2020.

2. Word Health Organization (WHO): Coronavirus disease 2019 (COVID-19) situation report-31. 2020.

3. Korean Society of Infectious Diseases, Korean Society of Pediatric Infectious Diseases, Korean Society of Epidemiology, Korean Society for Antimicrobial Therapy, Korean Society for Healthcare-associated Infection Control and Prevention, and Korea Centers for Disease Control and Prevention. Report on the epidemiological features of coronavirus disease 2019 (COVID-19) outbreak in the Republic of Korea from January 19 to March 2, 2020. J Korean Med Sci. 2020:35(10):e112.

4. Liu Y, Li J, Feng Y. Critical care response to a hospital outbreak of the 2019nCoV infection in Shenzhen, China. Crit Care. 2020;24(1):56.

5. Liew MF, Siow WT, MacLaren G, See KC. Preparing for COVID-19: early experience from an intensive care unit in Singapore. Crit Care. 2020;24(1):83.

6. Huh K, Shin HS, Peck KR. Emergent strategies for the next phase of COVID19. Infect Chemother. 2020;52(1):e6.

\section{Publisher's Note}

Springer Nature remains neutral with regard to jurisdictional claims in published maps and institutional affiliations.
Ready to submit your research? Choose BMC and benefit from:
- fast, convenient online submission
- thorough peer review by experienced researchers in your field
- rapid publication on acceptance
- support for research data, including large and complex data types
- gold Open Access which fosters wider collaboration and increased citations
- maximum visibility for your research: over $100 \mathrm{M}$ website views per year
At $\mathrm{BMC}$, research is always in progress.
Learn more biomedcentral.com/submissions 